\title{
Gibberellin-induced changes in the transcriptome of grapevine (Vitis labrusca $\times V$. vinifera) cv. Kyoho flowers
}

\author{
Chenxia Cheng ${ }^{1,2,3}$, Chen Jiao ${ }^{1,2}$, Stacy D Singer ${ }^{4}$, Min Gao ${ }^{1,2}$, Xiaozhao Xu' ${ }^{5}$, Yiming Zhou ${ }^{1}$, Zhi Li $i^{1,2}$, \\ Zhangjun Fei ${ }^{6,7}$, Yuejin Wang ${ }^{1,2}$ and Xiping Wang ${ }^{1,2^{*}}$
}

\begin{abstract}
Background: Gibberellins are well known for their growth control function in flower, fruit and seed development, and as such, exogenous gibberellic acid (GA) application plays an important role in viticulture. Unfortunately, the mechanism by which $\mathrm{GA}_{3}$ acts in the regulation of these complicated developmental processes in grape remains unclear.

Results: In the present study, we demonstrated that application of $\mathrm{GA}_{3}$ to 'Kyoho' grapevine inflorescences at pre-bloom promoted flower opening, and induced fruit coloring as well as seed abortion. In an attempt to obtain a deeper understanding of the molecular mechanisms driving these responses to $\mathrm{GA}_{3}$ treatment, we performed large-scale transcriptome sequencing of grape flowers following $\mathrm{GA}_{3}$ treatment using Illumina sequencing technology. Global expression profiles of $\mathrm{GA}_{3}$-treated and untreated grape flowers were compared and a large number of $\mathrm{GA}_{3}$-responsive genes were identified. Gene ontology $(\mathrm{GO})$ term classification and biochemical pathway analyses indicated that $\mathrm{GA}_{3}$ treatment caused changes in the levels of transcripts involved in cellular processes, reproduction, hormone and secondary metabolism, as well as the scavenging and detoxification of reactive oxygen species (ROS). These findings suggest that $\mathrm{GA}_{3}$-induced morphological alterations may be related to the control of hormone biosynthesis and signaling, regulation of transcription factors, alteration of secondary metabolites, and the stability of redox homeostasis.

Conclusions: Taken together, this comprehensive inflorescence transcriptome data set provides novel insight into the response of grape flowers to $\mathrm{GA}_{3}$ treatment, and also provides possible candidate genes or markers that could be used to guide future efforts in this field.
\end{abstract}

Keywords: Grape, Gibberellic acid, Gene expression, Pathways, RNA-seq, Transcriptome

\section{Background}

As sessile organisms, plants utilize hormones to adapt to developmental and environmental changes [1]. Among these hormones are the gibberellins, a large family of diterpenoid compounds that were first identified for their ability to stimulate the growth and elongation of rice seedlings [2], and have since been found to have diverse roles in plant development. These physiological functions

\footnotetext{
* Correspondence: wangxiping@nwsuaf.edu.cn

${ }^{1}$ State Key Laboratory of Crop Stress Biology in Arid Areas, College of Horticulture, Northwest A\&F University, Yangling 712100, Shaanxi, China ${ }^{2}$ Key Laboratory of Horticultural Plant Biology and Germplasm Innovation in Northwest China, Ministry of Agriculture, Northwest A\&F University, Yangling 712100, Shaanxi, China

Full list of author information is available at the end of the article
}

often differ between species, and include involvement in stem elongation, pollen maturation, seed germination, transition from vegetative growth to flowering, and fruit development $[3,4]$.

The endogenous biosynthesis and catabolism of gibberellins within plants, as well as the gibberellin response pathway, have been described in detail previously [5-13]. In brief, gibberellin biosynthesis in higher plants can be divided into three stages (Figure 1A): (1) production of ent-kaurene in proplastids; (2) conversion of ent-kaurene to $\mathrm{GA}_{12}$ via microsomal cytochrome $\mathrm{P} 450$ monooxygenases; and (3) formation of $\mathrm{C}_{20^{-}}$and $\mathrm{C}_{19-} \mathrm{GAs}$ in the cytoplasm [3,14]. Following its biosynthesis, gibberellin signaling in Arabidopsis is initiated through its binding to 


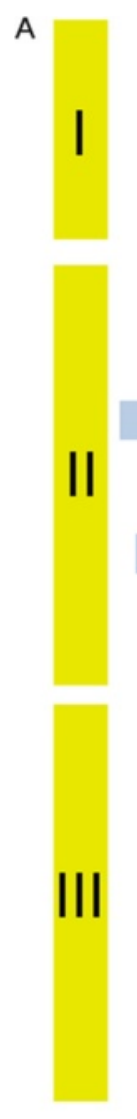

B

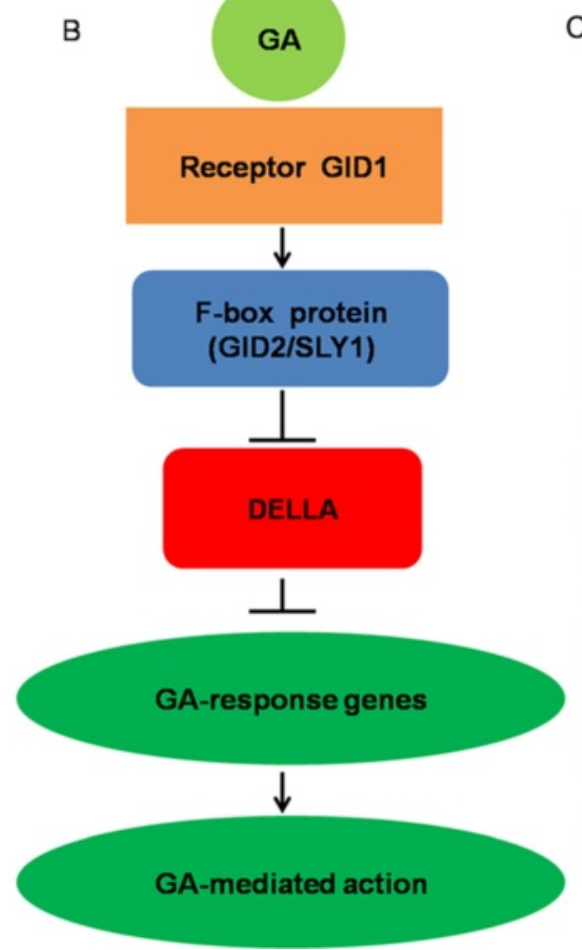

GA

GGPP

$\downarrow$ CPS

CDP

$\downarrow$ KS

ent-kaurene

$\downarrow$ Ko

ent-kaurenoic acid

$\downarrow$ KAO

$\downarrow$ KAO

$\mathrm{GA}_{9}, \mathrm{GA}_{20}$
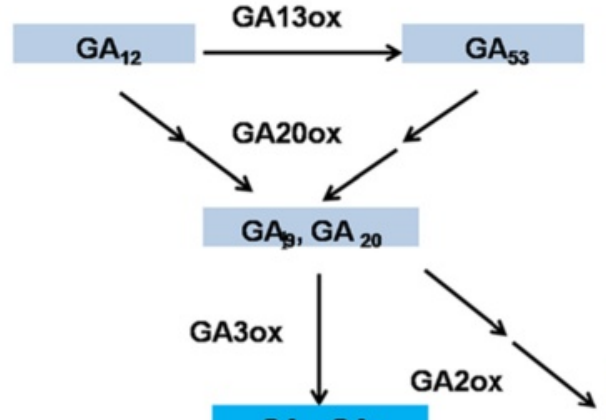

$\mathrm{GA}_{29}$-catabolite, $\mathrm{GA}_{51}$-catabolite

$\mathrm{GA}_{34}$-catabolite, $\mathrm{GA}_{8}$-catabolite

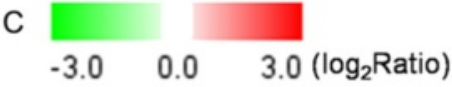

$$
=\frac{5}{\mathrm{~N}}
$$

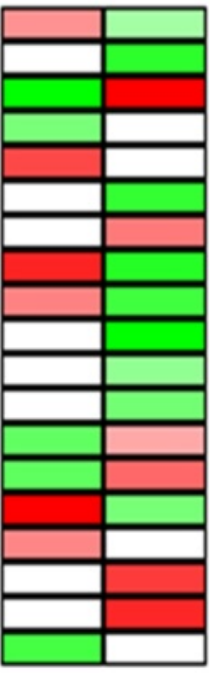

GSVIVG01036724001 KS

GSVIVG01026453001

GSVIVG01027572001

GSVIVG01017173001 GA3ox

GSVIVG01021488001

GSVIVG01012628001 GA20x

GSVIVG01028169001

GSVIVG01037191001

GSVIVG01027569001

GSVIVG01011037001

GSVIVG01022014001 Receptor

GSVIVG01010672001

GID1

GSVIVG01037525001

GSVIVG01025780001

GSVIVG01034878001

GSVIVG01015465001

GSVIVG:01019810001

GSVIVG01019809001

GSVIVG01030652001 
(See figure on previous page.)

Figure 1 Gibberellin biosynthetic and signaling pathways following $\mathrm{GA}_{3}$ treatment. (A) Gibberellin biosynthetic pathway; (B) Gibberellin signaling pathway; $(\mathbf{C})$ Heat map:differentially expressed grape genes with roles in GA biosynthesis and signaling following $\mathrm{GA}_{3}$ treatment in this study. Different shades of red and green denote the extent of the change according to the color bar provided ( $\log _{2}$ ratio of control); white indicates no change. GGPP, trans-geranyl-geranyl diphosphate; CDP, ent-copalyl diphosphate; CPS, copalyl diphosphate synthase; GA130x, GA 13-oxidase; GA20x, GA 2-oxidase; GA20ox, GA 20-oxidase; GA30x, GA 3-oxidase; KAO,ent-kaurenoic acid oxidase; KO,ent-kaurene oxidase; KS,ent-kaurene synthase. I, first stage of gibberellin biosynthesis; II, second stage of gibberellin biosynthesis; III, third stage of gibberellin biosynthesis.

the GA INSENSITIVE DWARF1 (GID1) receptor. This allows subsequent interaction between GID1 and DELLA proteins (GA INSENSITIVE [GAI], REPRESSOR OR GAI-3 [RGA], RGA-LIKE1 [RGL1], RGL2, and RGL3), which are transcriptional repressors that when unbound by GID1 down-regulate gibberellin response genes [15]. In the presence of gibberellin, the stable GID1-GA-DELLA complexes are recognized by the F-box protein SLEEPY1 (SLY1)-based SCF ${ }^{\mathrm{SLY} 1}$ complex, which ubiquitylates the DELLA proteins and causes their degradation by the $26 \mathrm{~S}$ proteasome [16].

The exogenous pre-bloom application of gibberellic acid $\left(\mathrm{GA}_{3}\right)$ to grapevine, which is an economically important crop that has long been an important component of the human diet, is commonly used to induce seedlessness $[17,18]$, establish early ripening [19], and enhance berry size in seedless cultivars [20-22]. However, despite its importance in viticulture, the precise mechanism by which GA elicits these complex outcomes remains elusive. Furthermore, the data that has accumulated thus far is somewhat conflicting. For instance, it has been reported that seedlessness induced by the application of $\mathrm{GA}_{3}$ to grape flowers before or during anthesis severely inhibited pollen germination and pollen tube growth [18], possibly due to the biosynthesis of pollen tube inhibitor(s), leading to the production of unfertilized ovules [23]. Conversely, our previous research suggested that ovules were fertilized normally and that the induced seedlessness following $\mathrm{GA}_{3}$ treatment may have been caused, at least in part, by an impairment of redox homeostasis in flowers/berries resulting in oxidative damage to the seeds [17].

Transcriptome sequences generated using high throughput techniques are more efficient, data-rich, and economical than EST-based and traditional PCR-based methods [24]. In grapevine, which is the first fruit crop to have its entire genome sequenced $[25,26]$, transcriptome sequencing has been conducted to identify microRNAs that are responsive to $\mathrm{GA}_{3}$ application [27]. Unfortunately, information regarding large-scale transcriptome alterations in response to exogenous $\mathrm{GA}_{3}$ application in grape remains scarce.

Therefore, in an effort to advance our understanding of the response to exogenous $\mathrm{GA}_{3}$ application in grape, we carried out RNA-Seq transcriptome analysis of grape flowers with and without $\mathrm{GA}_{3}$ treatment at two separate time-points using Illumina sequencing technology. Subsequent comparison of the global expression profiles of $\mathrm{GA}_{3}$-treated and untreated grape flowers allowed the identification of numerous $\mathrm{GA}_{3}$-responsive genes. Further detailed analyses of these genes yielded novel insight into $\mathrm{GA}_{3}$-response in grape, the results of which provide a number of putative candidate genes or markers that have the potential to be used to guide future studies in this field.

\section{Methods}

Plant material, $\mathrm{GA}_{3}$ treatment, and gibberellin content assay

Seeded grape cultivar 'Kyoho' (Vitis labrusca $\times V$. vinifera) plants were grown in an 8-year-old vineyard situated in an experimental field of Northwest A\&F University, Yangling, Shaanxi, China $\left(34^{\circ} 20^{\prime} \mathrm{N}, 108^{\circ} 24^{\prime} \mathrm{E}\right)$. Fifteen clusters were allowed to remain on each vine, and treatment was carried out $12 \mathrm{~d}$ before full bloom. Initially, clusters were soaked in 0.05\% Tween-20 (Roche, Basel, Switzerland) for $3 \mathrm{~s}$ to enhance subsequent uptake of the phytohormone. $\mathrm{GA}_{3}$ treatment was then carried out by soaking clusters in $100 \mathrm{mg} \mathrm{L}^{-1} \mathrm{GA}_{3}$ (Sigma-Aldrich, St. Louis, MO, USA) dissolved in a small amount of $100 \%$ ethanol for $5 \mathrm{~s}$ [28]. Untreated control clusters were subject to the same process without $\mathrm{GA}_{3}$.

For the gibberellin content assay, samples (three biological replicates of each) were collected immediately $1 \mathrm{~h}$, $12 \mathrm{~h}, 24 \mathrm{~h}$ and $72 \mathrm{~h}$ post-GA $\mathrm{GA}_{3}$ application. Extracts were purified and $30 \mu \mathrm{l}$ of each sample were subjected to HPLC analysis using a reverse phase column as described previously [29]. Analysis conditions were as follows: column temperature of $30^{\circ} \mathrm{C}$; mobile phase of methanol and $0.5 \%$ acetic acid [dissolved in redistilled water, 45:55 (v/v)]; and flow rate of $0.8 \mathrm{~mL} \mathrm{~min}^{-1}$. Statistical analyses of the data were conducted using independent-samples t-tests with the SPSS software (SPSS $17.0^{\circ}$, Chicago, IL, USA).

\section{RNA isolation}

Two biological replicates were used for all RNA-Seq experiments from each sample. Flowers collected from five independent vines were pooled to isolate RNA and were considered as one biological replicate. Treatment time points were $1 \mathrm{~h}$ and $24 \mathrm{~h}$ post-treatment for isolation of total RNA isolation, which was carried out using the E.Z.N.A. ${ }^{\circ}$ Plant RNA Kit according to the manufacturer's instructions (Omega Biotek, Norcross, GA, USA). RNA quality and quantity was assessed on a $1.2 \%$ denatured 
agarose gel and NanoDrop 1000 Spectrophotometer (Thermo Scientific, Wilmington, DE, USA), respectively.

\section{RNA-Seq analysis}

Strand-specific RNA-seq libraries were constructed as previously described [30] and two biological replicates were sequenced on an Illumina HiSeq 2000 system using the single-end mode for each treatment. The length of the reads was $50 \mathrm{bp}$. RNA-seq reads were first aligned to ribosomal RNA sequences using Bowtie [31] and aligned sequences were removed. The resulting filtered reads were then aligned to the grape genome using Tophat [32]. Following alignment, the count of mapped reads from each sample was derived and normalized to reads per kilobase of exon model per million mapped reads (RPKM). Differentially expressed genes (DEGs) between $\mathrm{GA}_{3}$-treated and control samples at each time point were identified using the DESeq 1.8.3 package [33] with the raw count data. Raw P values were adjusted for multiple testing using a false discovery rate (FDR) [34]. Genes with an FDR of less than 0.05 and fold-changes greater than 2 were regarded as DEGs. Gene Ontology (GO) functional classification in the set of differentially expressed genes and pathways that were affected by $\mathrm{GA}_{3}$ treatment were identified using the Plant MetGenMAP system [35].

\section{Quantitative RT-PCR analysis}

Quantitative real-time RT-PCR was carried out on two independent biological replicates of each sample, as well as three technical replicates, using a Bio-Rad iQ5 thermo cycler (Bio-Rad, Hercules, CA, USA). For each sample, $1 \mu \mathrm{g}$ of total RNA was converted into cDNA using PrimeScript ${ }^{\mathrm{rx}}$ RTase and an oligo dT primer (TaKaRa Biotechnology, Dalian, China) and was subsequently diluted six times with sterile water. Quantitative RT-PCR was performed using TaKaRa SYBR Premix Ex Taq ${ }^{\text {mi }}$ II (TaKaRa Biotechnology) and twelve primers set specific to known grape transcription factors (Additional file 1: Table S1). Cycling parameters were $95^{\circ} \mathrm{C}$ for $30 \mathrm{~s}, 40$ cycles of $95^{\circ} \mathrm{C}$ for $5 \mathrm{~s}$, and $60^{\circ} \mathrm{C}$ for $30 \mathrm{~s}$. For melting curve analysis, a program including $95^{\circ} \mathrm{C}$ for $15 \mathrm{~s}$, followed by a constant increase from $60^{\circ} \mathrm{C}$ to $95^{\circ} \mathrm{C}$, was included following the PCR cycles. The grape Actin1 gene (GenBank Accession number AY680701) was amplified with primers $\mathrm{F}$ (5'-GAT TCT GGT GAT GGT GTG AGT-3') and R (5'-GAC AAT TTC CCG TTC AGC AGT-3') as an internal control. Relative expression levels were analyzed using the iQ5 software and the normalizedexpression method.

\section{Results}

Morphological changes in inflorescences in response to $\mathrm{GA}_{3}$ application

To ascertain the effects of $\mathrm{GA}_{3}$ application on grapevine inflorescences, berries, and seed development, morphological analyses were carried out on grapevine inflorescence clusters that had been treated with solution bearing or lacking $\mathrm{GA}_{3}$, respectively, $12 \mathrm{~d}$ before full bloom. At $8 \mathrm{~d}$ posttreatment, the flowers of $\mathrm{GA}_{3}$-treated inflorescences had begun to open, while untreated flowers remained closed (Figure 2E-F), suggesting that GA stimulated the rate of flower development. Subsequently, as grape berries grew, the fruit of $\mathrm{GA}_{3}$-treated plants began to develop purple coloration $57 \mathrm{~d}$ after treatment ( $45 \mathrm{~d}$ after full bloom, DAF), while berries from untreated control plants remained fully green at this time point (Figure 2G-I). Finally, as expected, while seeds developed normally in untreated control berries, seedlessness was induced following $\mathrm{GA}_{3}$ application (Figure 2J).

\section{Effect of $\mathrm{GA}_{3}$ treatment on gibberellin content}

To determine the effect of $\mathrm{GA}_{3}$ application on gibberellin content, we assayed the amount of this phytohormone in grape flowers harvested $1 \mathrm{~h}, 12 \mathrm{~h}, 24 \mathrm{~h}$ and $72 \mathrm{~h}$ following $\mathrm{GA}_{3}$ treatment. As shown in Figure 3, $\mathrm{GA}_{3}$ application increased flower gibberellin content from $1 \mathrm{~h}$ to $24 \mathrm{~h}$ following treatment, with differences being significant at $1 \mathrm{~h}$ and $12 \mathrm{~h}$ post-application. Conversely, by $72 \mathrm{~h}$ following $\mathrm{GA}_{3}$ treatment, gibberellin content dropped to levels that were significantly less than those seen in untreated controls (Figure 3). By 6 days post-treatment gibberellin levels had evened out between treated and untreated controls (Additional file 2: Figure S1).

\section{RNA-Seq analysis of $\mathrm{GA}_{3}$-treated and untreated grape flower transcriptomes}

Since the gibberellin content of grape flowers was found to be increased between $1 \mathrm{~h}$ to $24 \mathrm{~h}$ following $\mathrm{GA}_{3}$ treatment, flowers were collected $1 \mathrm{~h}$ and $24 \mathrm{~h}$ after treatment with solution bearing or lacking $\mathrm{GA}_{3}$, and were used for RNA isolation and subsequent Illumina HiSeq 2000 sequencing. A total of eight samples were analyzed, with each condition having two biological replicates. After removing rRNA contaminated reads, clean reads were obtained (Additional file 1: Table S2). Reads mapping to the genome sequence made up approximately $80 \%$ of the reads, with the exception of one untreated $24 \mathrm{~h}$ post-treatment replicate $(79.02 \%)$. To further investigate the robustness of our RNA-Seq dataset, the correlation coefficients of the transcriptome profiles among the eight samples were calculated and were found to reach 0.99 between each set of biological replicates (Additional file 1: Table S3).

\section{Differential expression and Gene Ontology (GO) functional classification of $\mathrm{GA}_{3}$-treated and untreated grape flower transcriptomes}

The transcript abundance of each gene was estimated by reads per kilobase of exon model per million mapped reads (RPKM) and the DESeq 1.8.3 package was used to 

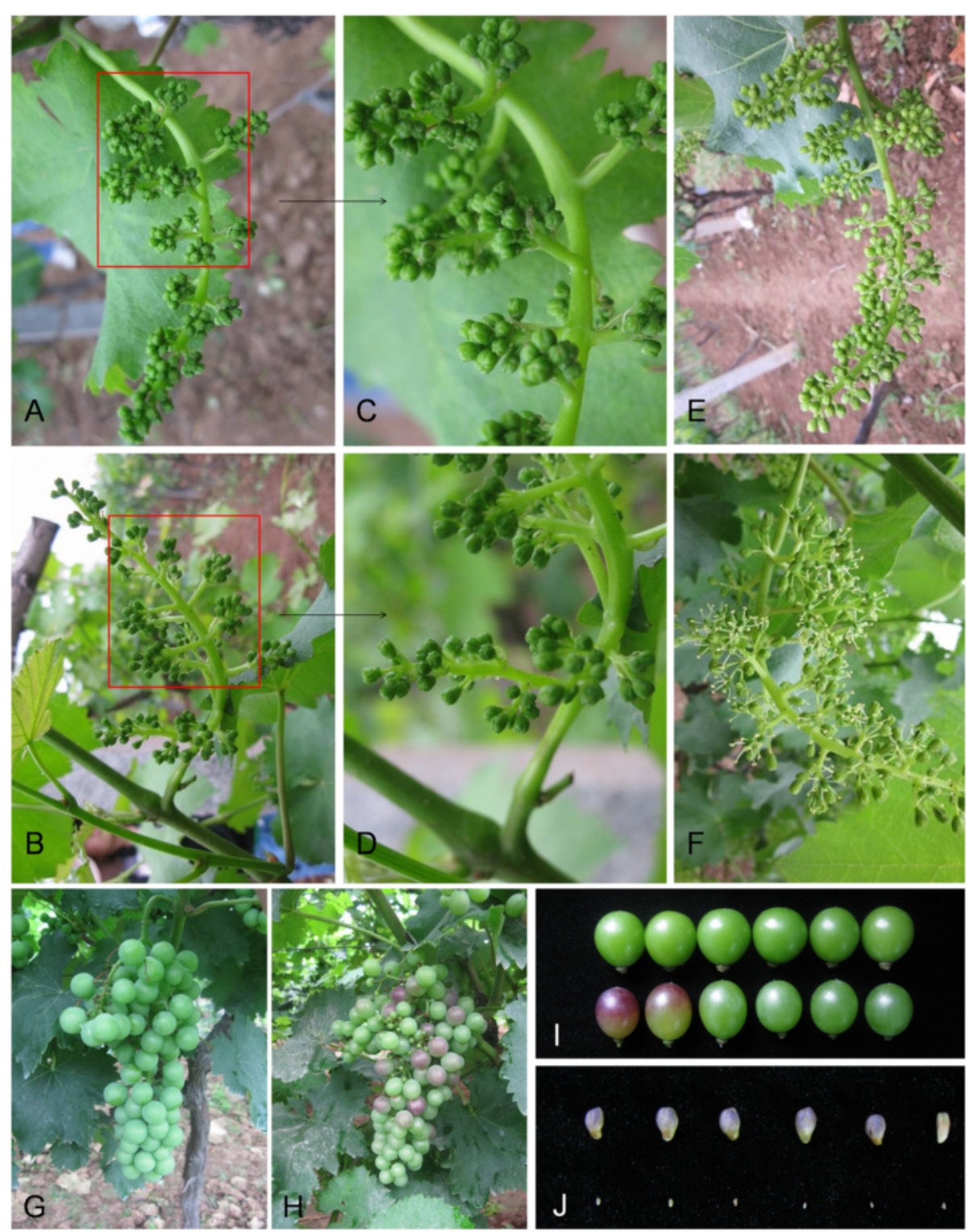

Figure 2 Inflorescences, clusters, berries and seeds from grape cv. 'Kyoho' following $\mathrm{GA}_{3}$ application. (A and B) Inflorescences from untreated control (A) and $\mathrm{GA}_{3}$-treated (B) plants $72 \mathrm{~h}$ after treatment; (C and $\left.\mathbf{D}\right)$ Magnification of the portions of (A) and (B) enclosed in a red frame, respectively; ( $\mathbf{E}$ and $\mathbf{F})$ Inflorescences from untreated control $\mathbf{( E )}$ and $\mathrm{GA}_{3}$-treated $\mathbf{( F )}$ plants $8 \mathrm{~d}$ after treatment. $(\mathbf{G}$ and $\mathbf{H}) \mathrm{Clusters}$ from untreated control (G) and $\mathrm{GA}_{3}$-treated $\mathbf{( H )}$ plants $57 \mathrm{~d}$ after treatment (45 d after full bloom, DAF); (I) Berries from untreated control (top-row) and $\mathrm{GA}_{3}$-treated (bottom-row) plants $57 \mathrm{~d}$ after treatment (45 DAF); (J) Seeds from untreated control (top-row) and GA - -treated (bottom-row) plants at maturity.

identify genes that were differentially expressed (DEGs) between $\mathrm{GA}_{3}$-treated and untreated control samples (Figure 4). Using a very stringent cutoff value, 1,281 genes with increased transcript abundance and 757 genes with decreased transcript abundance were identified in grape flowers $1 \mathrm{~h}$ after $\mathrm{GA}_{3}$ treatment (Figure $4 \mathrm{~A}$ ). Interestingly, an even larger number of genes exhibited differential expression $24 \mathrm{~h}$ following $\mathrm{GA}_{3}$ treatment, with 1,360 genes displaying increased transcript abundance and 1,353 genes showing decreased transcript abundance. As shown in Figure 4B, among these differentially expressed genes, 475 and 925 genes were upregulated only in grape flowers $1 \mathrm{~h}$ or $24 \mathrm{~h}$ following $\mathrm{GA}_{3}$ treatment, respectively (Additional file 3: Tables S1-S2); 316 and 604 genes were down-regulated only in grape flowers $1 \mathrm{~h}$ or $24 \mathrm{~h}$ following $\mathrm{GA}_{3}$ treatment, respectively (Additional file 3: Tables S3-S4); 435 genes were downregulated $1 \mathrm{~h}$ after $\mathrm{GA}_{3}$ treatment and then up-regulated $24 \mathrm{~h}$ after $\mathrm{GA}_{3}$ treatment (Additional file 3: Table S5); 743 genes were up-regulated $1 \mathrm{~h}$ after $\mathrm{GA}_{3}$ treatment and then 


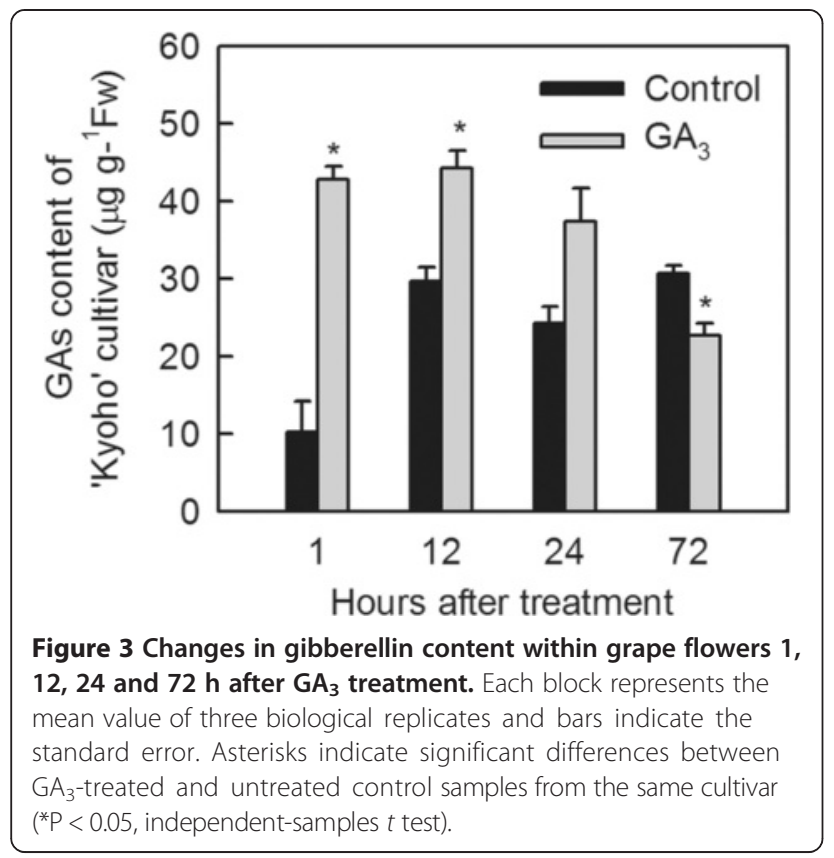

down-regulated $24 \mathrm{~h}$ after $\mathrm{GA}_{3}$ treatment (Additional file 3: Table S6); and somewhat surprisingly, only 6 genes were simultaneously down-regulated both $1 \mathrm{~h}$ and $24 \mathrm{~h}$ following $\mathrm{GA}_{3}$ treatment (Additional file 3: Table S7). Among these simultaneously down-regulated genes, genes encoding a Pelota protein, a putative aspartic proteinase nepenthesin-2 precursor, a putative hydroxysteroid dehydrogenase, a kelch repeat-containing F-box family protein and two hypothetical proteins were included.

Many DEGs with functions within the biological process category of GO were observed (Figure 5; Additional file 1: Table S4). For instance, a large number of genes were identified that displayed increased or decreased transcript abundance both $1 \mathrm{~h}$ and $24 \mathrm{~h}$ after $\mathrm{GA}_{3}$ treatment that play a role in cellular, metabolic and biosynthetic processes, response to stress, and transport. In addition, numerous other DEGs fell within a number of other interesting groups, including relating to reproduction, pollination, ripening, cell death, as well as flower, embryonic and post-embryonic development. Many of the DEGs identified above (Additional file 1: Table S5) were found to be involved in multiple biological processes, and those exhibiting $a \geq 10$ fold change from untreated samples are presented in Additional file 4. At $1 \mathrm{~h}$ post-GA $\mathrm{G}_{3}$ treatment, genes encoding a putative receptor protein kinase, polygalacturonase (PG), guanine nucleotide exchange factor, NAC domain protein and putative MADS-box transcription factor were up-regulated, while genes encoding purple acid phosphatase and Rop guanine nucleotide exchange factor were down-regulated. At $24 \mathrm{~h}$ post- $\mathrm{GA}_{3}$ treatment, genes encoding a lipid A export ATP-binding/permease protein MsbA, NAC domain protein, putative polygalacturonase, leucine-rich repeat receptor-like serine/threonine-protein kinase, putative receptor protein kinase, guanine nucleotide exchange factor and putative MADS-box transcription factor were down-regulated, while genes encoding purple acid phosphatase and gibberellin 20-oxidase were upregulated.

We also analyzed DEGs based on their molecular function, as well as their cellular component (Additional file 2: Figures S2-S3; Additional file 1: Tables S6-S7). Within the molecular function category, groups with the highest abundance of DEGs included those relating to protein binding and catalytic activity, while other interesting groups included nucleotide and carbohydrate binding, as well as hydrolase, transferase, transporter, receptor, signal transducer and transcription factor activities (Additional file 2: Figure S2; Additional file 1: Table

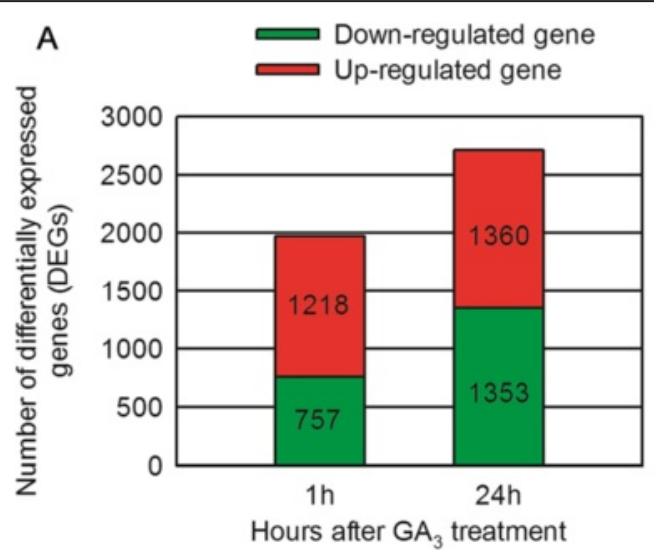

B

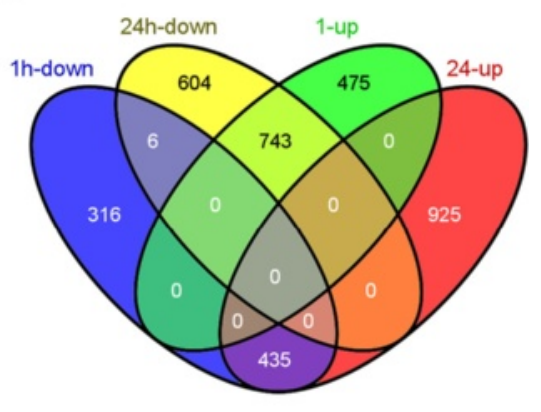

Hours after $\mathrm{GA}_{3}$ treatment

Figure 4 Gene Expression Comparisons. (A) Number of DEGs ( $P$ value $\leq 0.05$ and fold-change $\geq 2$ ) between $G A_{3}$-treated and untreated samples; (B) Number of DEGs between $1 \mathrm{~h}$ and $24 \mathrm{~h}$ following $\mathrm{GA}_{3}$ treatment. Overlapping sets of up-regulated or down-regulated genes between $1 \mathrm{~h}$ and $24 \mathrm{~h}$ following $\mathrm{GA}_{3}$ application are shown in the Venn diagram. 


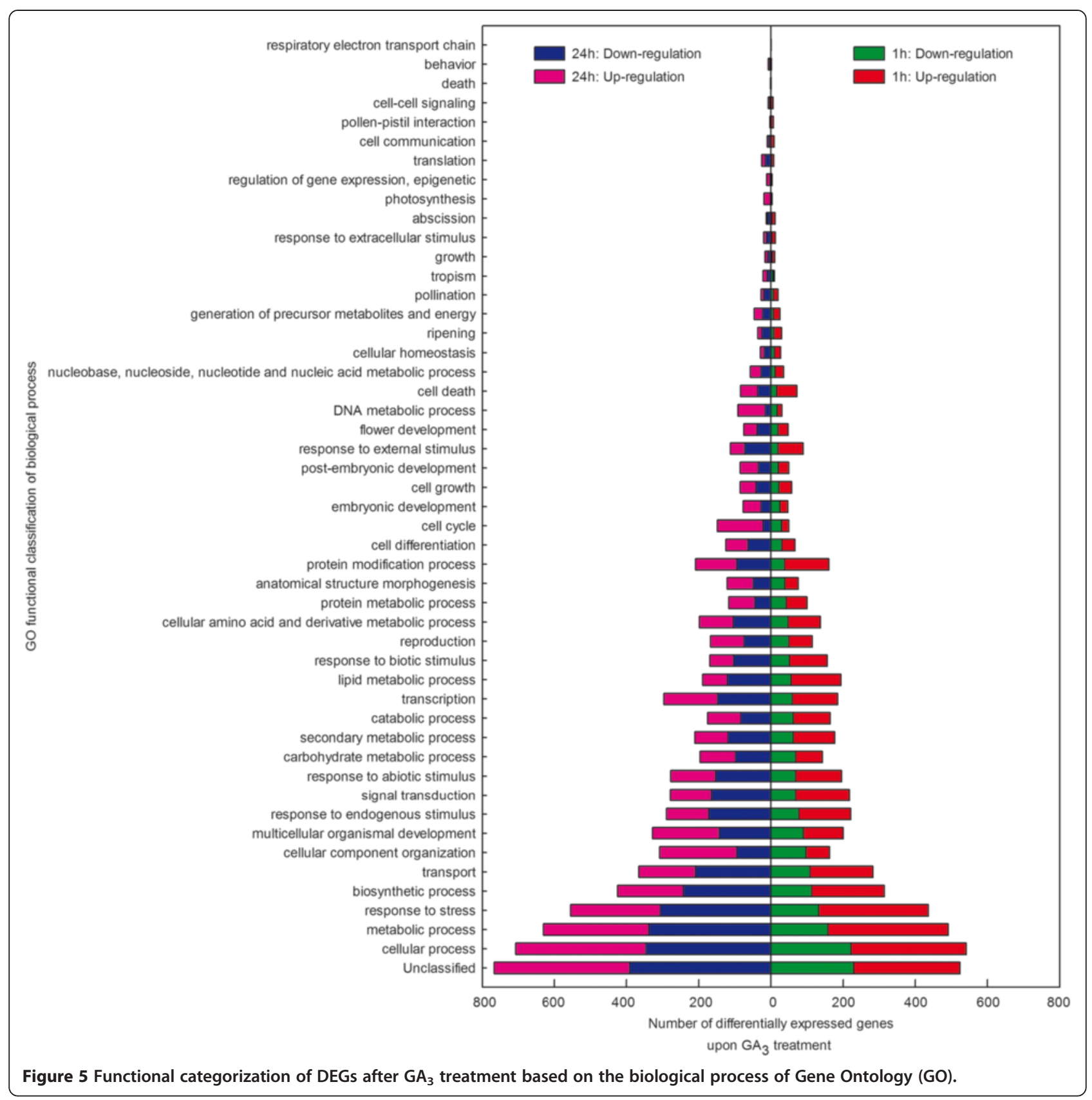

S6). Within the cellular component category, the greatest number of DEGs fell within the plasma membrane, nucleus, and cytoplasm groups (Additional file 2: Figure S3; Additional file 1: Table S7).

\section{Effect of $\mathrm{GA}_{3}$ treatment on gibberellin biosynthetic and signaling pathway-related genes}

A large number of DEGs with involvement in GA biosynthetic and signaling pathways were also identified (Figure 1C; Additional file 1: Table S8). The expression of the GA biosynthesis gene KS (GSVIVG01036724001) was up-regulated $1 \mathrm{~h}$ following $\mathrm{GA}_{3}$ treatment and down-regulated $24 \mathrm{~h}$ following treatment. In addition, genes encoding GA20oxs (GSVIVG01026453001 and GSVIVG01027572001) and GA3ox (GSVIVG010171730 $01)$ were down-regulated following $\mathrm{GA}_{3}$ application. The expression of genes encoding the GA-inactivating enzymes, GA2oxs, also exhibited differential expression following the application of $\mathrm{GA}_{3}$, while GSVIVG0102146800 and GSVIVG01028169001 were up-regulated $1 \mathrm{~h}$ and $24 \mathrm{~h}$ following treatment, respectively, GSVIVG01012628001 was down-regulated $24 \mathrm{~h}$ after treatment. This feedback 
mechanism also appears to operate at the level of GA perception, with $\mathrm{GA}_{3}$ negatively regulating the expression of the gibberellin receptor GID1 (Figure 1C; Additional file 1: Table S8). Of the seven grape genes encoding GID1, GSVIVG0102578000 and GSVIVG01037525001 were down-regulated $1 \mathrm{~h}$ after treatment, while GSVIVG010106 72001, GSVIVG01011037001, GSVIVG01022014001, GSV IVG01027569001 and GSVIVG01037191001 were downregulated $24 \mathrm{~h}$ after treatment. In contrast, with the exception of GSVIVG01030652001, the remaining four genes encoding DELLA proteins exhibited up-regulation following $\mathrm{GA}_{3}$ treatment.

\section{$\mathrm{GA}_{3}$-responsive transcription factors}

A large number of differentially expressed $\mathrm{GA}_{3}$-responsive transcription factors (TFs) were identified in this study (Figure 6; Additional file 2: Figure S4; Additional file 1: Table S9). In total, 157 (7.7\% of total DEGs) and 175 (7.23\% of total DEGs) DEGs were classed into 30 distinct transcription factor families $1 \mathrm{~h}$ and $24 \mathrm{~h}$ after $\mathrm{GA}_{3}$ treatment, respectively. One hour following treatment, 103 genes encoding transcription factors were found to be up-regulated and 54 were down-regulated. Similarly, 100 genes encoding transcription factors were found to be up-regulated and 124 down-regulated $24 \mathrm{~h}$ after $\mathrm{GA}_{3}$ application. The majority of transcription factor-encoding DEGs were members of the AP2/EREBP family, followed by MYB, bHLH, WRKY, NAC, and ARF families. In the case of the AP2/EREBP family, 16 genes were up-regulated $1 \mathrm{~h}$ following $\mathrm{GA}_{3}$ treatment, whereas 32 genes were down-regulated $24 \mathrm{~h}$ post-treatment. Similarly, DEGs belonging to the WRKY, NAC, TIFY, GRAS, MADS-box and PLATZ families were for the most part induced $1 \mathrm{~h}$ following $\mathrm{GA}_{3}$ treatment and repressed $24 \mathrm{~h}$ post-treatment. In the case of both MYB and bHLH family DEGs, a higher number of up-regulated genes were observed 1 and $24 \mathrm{~h}$ post-treatment than down-regulated genes. In the case of ARF, GRF, HB, TCP and zf-HD family DEGs, there generally tended to be more up-regulation occurring at $24 \mathrm{~h}$ post-treatment than down-regulation.

\section{Quantitative real-time RT-PCR (qRT-PCR) validation of DEGs from RNA-Seq}

To further validate our RNA-seq expression profile data, we performed qRT-PCR assays on twelve genes encoding a selection of transcription factors (Figure 7). Our qRTPCR results revealed that in every case, the expression trends of these genes corresponded to our RNA-Seq data. To obtain measurements of the correlation between the RNA-Seq and qRT-PCR data, we generated scatterplots using the $\log _{2}$-fold change between RNA-Seq and qRTPCR data (Additional file 2: Figure S5) and found a close correlation $\left(R^{2}=0.83\right)$ between the two methods.

\section{$\mathrm{GA}_{3}$-induced pathways in grape flowers}

In order to assess the functional roles of $\mathrm{GA}_{3}$-responsive genes involved in different biochemical pathways, we identified the pathways affected by $\mathrm{GA}_{3}$ application based on our expression profiling analyses. A total of 70 and 85 biochemical pathways were significantly affected by $\mathrm{GA}_{3}$ treatment ( $\mathrm{p}$ value $<0.05$ ) at $1 \mathrm{~h}$ and $24 \mathrm{~h}$ following application, respectively (Figure 8; Additional file 1: Table S10). These pathways comprised the biosynthesis or degradation of diverse metabolites including hormones, sugars and polysaccharides, amino acids, fatty acids and lipids, and secondary metabolites.

Among the hormone-related pathways, jasmonic acid biosynthesis (Additional file 2: Figure S6), salicylate biosynthesis (Additional file 2: Figure S7), ethylene biosynthesis from methionine (Additional file 2: Figure S8), cytokinin degradation (Additional file 2: Figure S9) and gibberellin biosynthesis (Figure 1) included DEGs that exhibited significant alterations following $\mathrm{GA}_{3}$ application. In the case of the jasmonic acid biosynthetic pathway, DEGs were up-regulated $1 \mathrm{~h}$ after treatment and were downregulated $24 \mathrm{~h}$ after treatment, and included lipoxygenases, allene oxide synthases, allene oxide cyclase and 12-oxophytodienoate reductases (Additional file 2: Figure S6). In terms of ethylene biosynthesis from methionine (Additional file 2: Figure S8), the gene encoding the key enzyme 1-aminocyclopropane-1-carboxylate synthase (ACS, GSVIVG01026962001) was up-regulated $1 \mathrm{~h}$ following treatment and down-regulated $24 \mathrm{~h}$ following treatment, while two other genes (GSVIVG01005455001 and GSVIVG01019920001) were down-regulated $24 \mathrm{~h}$ following treatment. Furthermore, the expression of five genes encoding cytokinin oxidases (GSVIVG01028586001, GSVIVG01006081001, GSVIVG01006150001, GSVIVG01 028599001 and GSVIVG01028610001), which are involved in cytokinin degradation, were induced by more than 36-fold $24 \mathrm{~h}$ following $\mathrm{GA}_{3}$ treatment (Additional file 2: Figure S9). Intriguingly, one of these (GSVIVG010286100 01) was up-regulated upwards of 340-fold.

Secondary metabolic pathways such as the biosynthesis of farnesene (Additional file 2: Figure S10), flavonoids (Additional file 2: Figure S11), linalool, phenylpropanoids (Additional file 2: Figure S12), chlorogenic acid (Additional file 2: Figure S12), monoterpenes, simple coumarin, free phenylpropanoid acid and geranylgeranyldiphosphate (via MEP) were significantly altered both $1 \mathrm{~h}$ and $24 \mathrm{~h}$ following $\mathrm{GA}_{3}$ treatment. Within the farnesene biosynthetic pathway (Additional file 2: Figure S10), 31 genes encoding terpenoid synthases were highly upregulated $1 \mathrm{~h}$ after $\mathrm{GA}_{3}$ treatment, while 27 genes encoding terpenoid synthases were down-regulated and three genes were up-regulated $24 \mathrm{~h}$ after treatment. In the case of flavonoid biosynthesis (Additional file 2: Figure S11), genes encoding the key chalcone synthases displayed 22- 


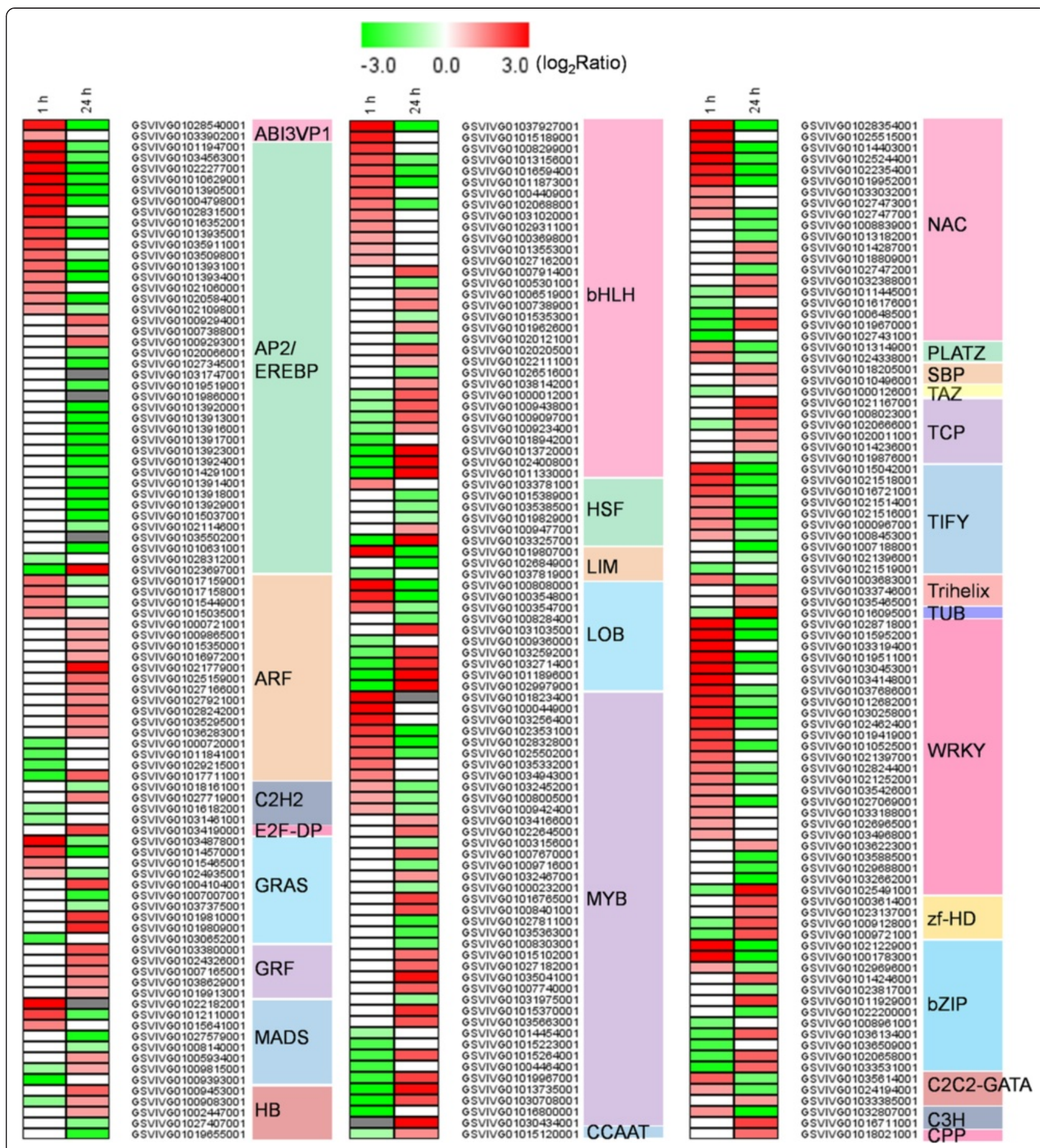

Figure 6 Differentially expressed genes encoding transcription factors following $\mathrm{GA}_{3}$ treatment. Different shades of red and green express the extent of the change according to the color bar provided ( $\log _{2}$ ratio of control); white indicates no change; gray indicates that no transcript was detected in $\mathrm{GA}_{3}$-treated samples.

66-fold increases in their expression $1 \mathrm{~h}$ after $\mathrm{GA}_{3}$ treatment, while 3-7-fold decreases were noted in their expression $24 \mathrm{~h}$ after treatment. Differentially expressed genes encoding enzymes involved in the phenylpropanoid biosynthetic pathway, as well as the related chlorogenic acid biosynthetic pathway (Additional file 2: Figure S12), included phenylalanine ammonia-lyases, cinnamate 4-hydroxylase, 4-coumarate CoA ligases, hydroxycinnamoyl-CoA shikimate/quinate hydroxycinnamoyltransferase, caffeoyl-CoA O-methyltransferases and cinnamoyl-CoA reductases. Interestingly, the majority of DEGs encoding PALs, which are the enzymes that catalyze the first step in this 


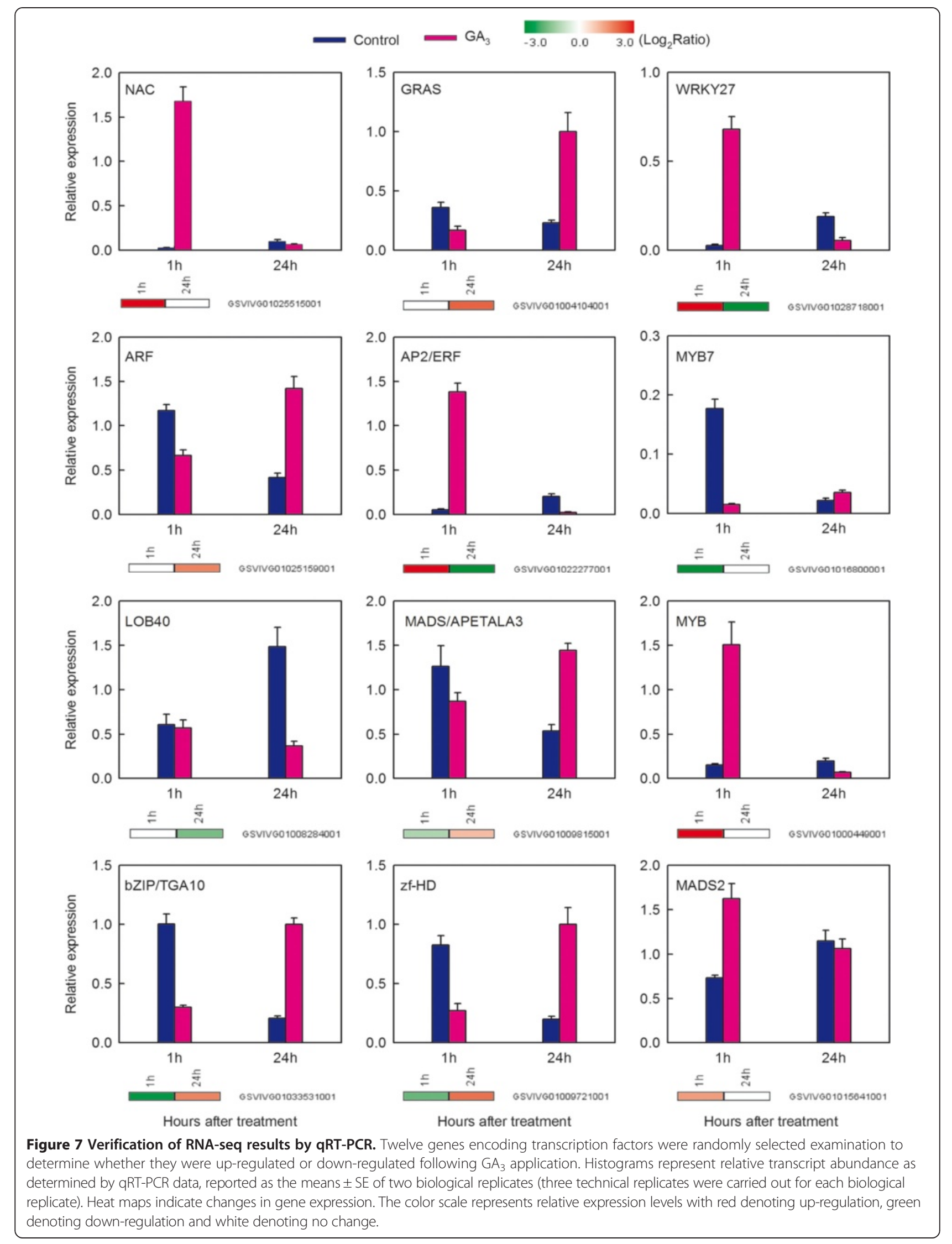




\begin{tabular}{|c|c|c|c|c|c|}
\hline$\cong$ & 亮 & \multirow[b]{2}{*}{ avenacin biosynthesis } & $\cong$ & 兴 & \\
\hline & & & & & $\begin{array}{l}\text { simple coumarins biosynthesis } \\
\text { spermine biosynthesis }\end{array}$ \\
\hline & & \multirow{3}{*}{$\begin{array}{l}\text { Fe(III)-reduction and Fe(II) transport } \\
\text { GDP-mannose metabolism }\end{array}$} & & & starch degradation \\
\hline & & & & & \multirow{2}{*}{$\begin{array}{l}\text { sucrose degradation III } \\
\text { superpathway of geranylgeranyldiphosphate biosynthesis II (via MEP) }\end{array}$} \\
\hline & & & & & \\
\hline & & \multirow{2}{*}{$\begin{array}{l}\text { jasmonic acid biosynthesis } \\
\text { linalool biosynthesis }\end{array}$} & & & $\begin{array}{l}\text { superpathway of phenylalanine, tyrosine, and tryptophan biosynthesis } \\
\text { superpathway of polyamine biosynthesis ॥I }\end{array}$ \\
\hline & & & & & \multirow{2}{*}{$\begin{array}{l}\text { superpathway of pyridoxal } 5 \text {-phosphate biosynthesis and salvage } \\
\text { superpathway of serine and glycine biosynthesis I }\end{array}$} \\
\hline & & \multirow{3}{*}{$\begin{array}{l}\text { mannitol degradation II } \\
\text { methylglyoxal degradation I } \\
\text { monoterpene biosynthesis }\end{array}$} & & & \\
\hline & & & & & \\
\hline & & & & & $\beta$-alanine biosynthesis I \\
\hline & & \multirow{3}{*}{$\begin{array}{l}\text { 13-LOX and } 13-\mathrm{HPL} \text { pathway } \\
\text { acrylonitrile degradation } \\
\text { adenosine nucleotides de novo biosynthesis }\end{array}$} & & & alanine biosynthesis I \\
\hline & & & & & cholesterol biosynthesis I \\
\hline & & & & & $\begin{array}{l}\text { cholesterol biosynthesis II (via 24,25-dihydrolanosterol) } \\
\text { cholesterol biosynthesis III (via desmosterol) }\end{array}$ \\
\hline & & \multirow{2}{*}{$\begin{array}{l}\text { aldoxime degradation } \\
\text { cellulose biosynthesis }\end{array}$} & & & \multirow{2}{*}{$\begin{array}{l}\text { epoxysqualene biosynthesis } \\
\text { galacto sylcyclitol biosynthesis }\end{array}$} \\
\hline & & & & & \\
\hline & & cytokinins degradation & & & gibberellin biosynthesis I (non C-3, non C- 13 hydroxylation) \\
\hline & & \multirow{4}{*}{$\begin{array}{l}\text { divinyl ether biosynthesis II (13-LOX) } \\
\text { ethylene biosynthesis from methionine } \\
\text { flavonoid biosynthesis }\end{array}$} & & & \multirow{2}{*}{$\begin{array}{l}\text { gibberellin biosynthesis II (early C-3 hydroxylation) } \\
\text { gibberellin biosynthesis III (early C-13 hydroxylation) } \\
\text { guanosine nucleotides de novo biosynthesis }\end{array}$} \\
\hline & & & & & \\
\hline & & & & & \multirow{6}{*}{$\begin{array}{l}\text { guanosine nucleotides de novo biosynthesis } \\
\text { isoleucine degradation I } \\
\text { plant sterol biosynthesis } \\
\text { sucrose biosynthesis } \\
\text { superpathway of geranylgeranyldiphosphate biosynthesis I (via mevalonate) } \\
\text { valine biosynthesis }\end{array}$} \\
\hline & & & & & \\
\hline & & \multirow{8}{*}{$\begin{array}{l}\text { folate transformations } \\
\text { formylTHF biosynthesis II } \\
\text { free phenylpropanoid acid biosynthesis } \\
\text { gluconeogenesis } \\
\text { glucosinolate biosynthesis from homomethionine } \\
\text { glutamate biosynthesis I } \\
\text { glutamate biosynthesis III } \\
\text { glutamine degradation II }\end{array}$} & & & \\
\hline & & & & & \\
\hline & & & & & \\
\hline & & & & & \\
\hline & & & & & $\begin{array}{l}\text { very long chain fatty acid biosynthesis } \\
\text { saponin biosynthesis I } \\
\text { suberin biosynthesis }\end{array}$ \\
\hline & & & & & suberin biosynthesis \\
\hline & & & & & sucrose degradation I \\
\hline & & & & & $\begin{array}{l}\text { ryplopnan degradation vir (via indole-s-pyruvate) } \\
\text { valine degradation I }\end{array}$ \\
\hline & & glycine biosynthesis I & & & valine degradation II \\
\hline & & glycolysis I & & & very long chain fatty acid biosynthesis \\
\hline & & glycolysis IV (plant cytosol) & & & a-amyrin biosynthesis \\
\hline & & homogalacturonan biosynthesis & & & asparagine biosynthesis I \\
\hline & & homogalacturonan degradation & & & asparagine biosynthesis II \\
\hline & & lactose degradation III & & & colanic acid building blocks biosynthesis \\
\hline & & leucine degradation I & & & glycolipid desaturation \\
\hline & & melibiose degradation & & & mevalonate degradation \\
\hline & & methionine degradation I (to homocysteine) & & & NAD biosynthesis I (from aspartate) \\
\hline & & methylerythritol phosphate pathway & & & phenylpropanoid biosynthesis, initial reactions \\
\hline & & $\begin{array}{l}\text { methylquercetin biosynthesis } \\
\text { nitrate reduction }\end{array}$ & & & phospholipid desaturation \\
\hline & & phenylalanine degradation II (anaerobic) & & & purine degradation I (aerobic) \\
\hline & & phenylpropanoid biosynthesis & & & pyrimidine ribonucleotides interconversion \\
\hline & & photorespiration & & & \\
\hline & & pyridoxal 5 -phosphate biosynthesis & & & superpathway of purines degradation in plants \\
\hline & & removal of superoxide radicals & & & triacylglycerol biosynthesis \\
\hline & & Rubisco shunt & & & triacylglycerol degradation \\
\hline & & S-adenosyl-L-methionine cycle & & & wax esters biosynthesis I \\
\hline & & S-adenosylmethionine biosynthesis & & & wax esters biosynthesis II \\
\hline
\end{tabular}

biosynthetic pathway and also promote the synthesis of salicylic acid (SA), were up-regulated following $\mathrm{GA}_{3}$ application (Additional file 2: Figure S7).

Among the sugar and polysaccharide-related pathways, homogalacturonan degradation (Additional file 2: Figure S13), cellulose biosynthesis (Additional file 2: Figure S14), starch degradation (Additional file 2: Figure S15), DIMBOA-glucoside degradation, lactose degradation (Additional file 2: Figure S16) and sucrose degradation (Additional file 2: Figure S17) were represented. In particular, highly significant changes were observed in DEGs with involvement in homogalacturonan degradative and cellulose biosynthetic pathways (Figure 8; Additional file 1: Table S10).

In addition, the expression of genes within pathways related to the scavenging and detoxification of reactive oxygen species (ROS), including the 13-LOX and 13-HPL pathway (Additional file 2: Figure S18), glutathionemediated detoxification (Additional file 2: Figure S19) and removal of superoxide radicals (Additional file 2: Figure S20), were also found to be significantly affected following $\mathrm{GA}_{3}$ treatment. DEGs within these pathways included lipoxygenases, peroxidases (GSVIVG01032517001 and GSVIVG01032513001), glutathione $S$-transferase and superoxide dismutase.

\section{Discussion}

Gibberellins are involved in multiple aspects of growth and development, including stem elongation, seed maturation and germination, floral induction, pollen germination, and pollen tube growth $[3,7,10,36]$. In grapevine, the effects of GA application on berry enlargement, the induction of seedlessness in seeded cultivars and ripening have been the subject of study for quite some time [17,19,37-39]. Interestingly, we have previously demonstrated that the exogenous pre-bloom application of $\mathrm{GA}_{3}$ inhibited berry growth in seeded 'Kyoho' and 'Red Globe' cultivars, yet stimulated berry growth in 'Thompson Seedless' [17]. Similarly, it has also been shown that berry growth was inhibited in the seeded grape cultivar 'Emperador' and promoted in the seedless cultivar 'Emperatriz' upon $\mathrm{GA}_{3}$ application [22]. Therefore, we supposed that whether the exogenous pre-bloom application of $\mathrm{GA}_{3}$ to grape inflorescences stimulates berry 
production may be cultivar-dependent. Here, we confirm that the exogenous pre-bloom application of $\mathrm{GA}_{3}$ to 'Kyoho' inflorescences promotes flower opening (Figure 2A-F), fruit coloring (Figure 2G-I), and seed abortion (Figure 2J). To advance our understanding of these GA-induced responses in grape, we carried out RNA-Seq transcriptome analysis of grape flowers and compared results between $\mathrm{GA}_{3}$-treated and untreated samples.

In order to determine the appropriate time points following $\mathrm{GA}_{3}$ treatment at which our RNA-Seq analysis should be conducted, we assayed the gibberellin content in $\mathrm{GA}_{3}$ treated and untreated flowers and found that levels were elevated between $1 \mathrm{~h}$ and $24 \mathrm{~h}$ post-treatment, and then dropped $72 \mathrm{~h}$ following application (Figure 3 ). These results were consistent with previous findings in which $\mathrm{GA}_{3}$ application was found to substantially increase berry GA content for $24 \mathrm{~h}$ and then dropped to levels that were similar to untreated controls 3 days post-treatment [20]. It has been shown that the uptake percentage for $\mathrm{GA}_{3}$ was approximately $6.8 \% 24 \mathrm{~h}$ after $\mathrm{GA}_{3}$ application [40]. Therefore, we speculate that the observed increase in GA content in $\mathrm{GA}_{3}$ treated tissues stemmed from $\mathrm{GA}_{3}$ treatment. As a result of these findings, we collected our $\mathrm{GA}_{3}$-treated/untreated flower samples for RNA isolation and subsequent transcriptome analysis $1 \mathrm{~h}$ and $24 \mathrm{~h}$ following treatment.

In each case, approximately $80 \%$ of the obtained reads could be assigned to grape genes and were used for gene expression profiling (Additional file 1: Table S2). The robustness of this RNA-Seq dataset was revealed by the high correlation observed among biological replicates (Additional file 1: Table S3), while the very close consistency between relative expression levels obtained with RNA-Seq and qRT-PCR (Figure 7; Additional file 2: Figure S5) indicates the legitimacy of both sets of results. We detected 1975 and 2713 DEGs in grape flowers $1 \mathrm{~h}$ and $24 \mathrm{~h}$ following application with $\mathrm{GA}_{3}$, respectively (Figure 4A), indicating that the alterations in grape inflorescence morphology noted following $\mathrm{GA}_{3}$ treatment are likely mediated through modifications in genomic expression profiles. The multiplicity of GO categories found to be enriched in $\mathrm{GA}_{3}$-treated tissues (Figure 5; Additional file 1: Table S4) hints at the complexity of the response.

In this study, at both $1 \mathrm{~h}$ and $24 \mathrm{~h}$ following $\mathrm{GA}_{3}$ treatment, up-regulated genes tended to fall into categories encompassing cellular, protein modification and catabolic processes, as well as multicellular organismal development and reproduction (Figure 5; Additional file 1: Table S4). Furthermore, many post-GA $\mathrm{G}_{3}$ treatment DEGs were found to be involved in various aspects of flower, fruit and embryonic development, as well as pollination and cell death (Additional file 1: Table S5). These processes correspond well with observed morphological alterations that occur following the application of $\mathrm{GA}_{3}$, including the promotion of flower opening (Figure 2A-F) and fruit coloring (Figure 2G-I), as well as the induction of seed abortion (Figure 2J). In addition, we identified many DEGs that are involved in various biochemical pathways, including those comprising the biosynthesis or degradation of diverse metabolites including hormones, sugars and polysaccharides, amino acids, fatty acids and lipids, and secondary metabolites (Figure 8; Additional file 1: Table S10). These findings imply that $\mathrm{GA}_{3}$ application to grape flowers has a fairly comprehensive impact on their metabolism.

Plant hormones regulate essentially all physiological and developmental processes during a plant's life cycle. These structurally diverse compounds include abscisic acid, auxins, brassinosteroids, cytokinins (CTKs), GAs, ethylene, and jasmonates (JAs) [41]. In the present study, the expression of many genes involved in the biosynthesis of jasmonic acid, salicylic acid, ethylene and gibberellin, as well as the degradation of cytokinins, were significantly altered following $\mathrm{GA}_{3}$ application (Figure 8, Additional file 1: Table S10). Genes involved in jasmonic acid biosynthesis were up-regulated $1 \mathrm{~h}$ after $\mathrm{GA}_{3}$ treatment and down-regulated $24 \mathrm{~h}$ post-application (Additional file 2: Figure S6). It has been found previously that GA promotes the expression of jasmonate (JA) biosynthetic genes and induces JA accumulation in flowers [42,43], which correlates well with our results. Since it has been demonstrated that both GA and JA play important roles during stamen development [44-48], it is possible that at least some aspects of the floral/reproductive alterations apparent in grape following $\mathrm{GA}_{3}$ application are the result of increased levels of JA. Similarly, we found that five cytokinin oxidase/dehydrogenase $(C K X)$ genes, which encode enzymes that are responsible for the breakdown of cytokinins $[49,50]$, were substantially up-regulated $24 \mathrm{~h}$ following $\mathrm{GA}_{3}$ application (Additional file 2: Figure S9). Since cytokinins play a role in gynoecia and fruit morphogenesis and patterning [51], embryonic and post-embryonic growth and development [52-54], and can also have an effect on seed number [50], it is likely that a reduction in their levels would interfere with seed development, and thus may be involved in $\mathrm{GA}_{3}$-induced seedlessness (Figure 2J).

Conversely, we found that $24 \mathrm{~h}$ following $\mathrm{GA}_{3}$ treatment, several genes with involvement in ethylene biosynthesis (ACSs, GSVIVG0102696200, GSVIVG01005455001 and GSVIVG01019920001) were down-regulated (Additional file 2: Figure S8), which may result in a reduction in ethylene production flowers. Intriguingly, ethylene plays important functions in tissue differentiation, initiation of flowering, anthocyanin synthesis, floral opening and senescence, pollination and fruit ripening [55]. In particular, ethylene is known to delay flowering by repressing GA levels [56]. Therefore, it is 
feasible that $\mathrm{GA}_{3}$-induced premature floral opening may be related to the down-regulation of ethylene biosynthetic genes.

In terms of effects of $\mathrm{GA}_{3}$ application on the biosynthesis of this hormone itself, we found that the majority of GA20ox and GA3ox genes, which catalyze the penultimate and final steps, respectively, in the formation of bioactive GAs (GA1 and GA4) [7,8], were down-regulated following application of $\mathrm{GA}_{3}$ (Figure 1C; Additional file 1: Table S8). In contrast, the genes encoding GA2ox (GSVIVG01021468 00 and GSVIVG01028169001) were up-regulated following GA treatment (Figure 1C; Additional file 1: Table S8). Both of these findings correspond well with previous studies [7,8,57-59]. These data suggest that feedback regulation may control the concentration of active GAs after exogenous $\mathrm{GA}_{3}$ application, which could have an effect on the response of grape flowers to this hormone.

GA signaling is now understood to hinge on DELLA proteins, which in the absence of GA negatively regulate GA response genes $[15,60]$. In the presence of GA, which binds to the GID1 receptor, interaction is enabled between GID1 and DELLA proteins, which causes the subsequent degradation of the latter. It has been found previously that genes encoding GA receptors and DELLA proteins were down-regulated and up-regulated, respectively, following GA treatment [57,61], which agrees with our results (Figure 1B-C; Additional file 1: Table S8).

In addition, we also found that 157 (7.7\% of total DEGs) and 175 (7.23\% of total DEGs) DEGs $1 \mathrm{~h}$ and $24 \mathrm{~h}$ after $\mathrm{GA}_{3}$ treatment, respectively, encoded transcription factors. Members of the AP2/EREBP transcription factor family made up the majority of these DEGs, followed by members of MYB, bHLH, WRKY, NAC, and ARF families (Figure 6; Additional file 2: Figure S4; Additional file 1: Table S9). Since transcription factors play essential roles in the regulatory networks of many developmental processes, it is probable that the alterations in their levels play a role in the observed morphological changes associated with $\mathrm{GA}_{3}$ application in grape.

Interestingly, in this study, venn diagram analysis (Figure 4B) displayed six simultaneously down-regulated genes at both $1 \mathrm{~h}$ and $24 \mathrm{~h}$ following $\mathrm{GA}_{3}$ application. One of these six genes that was very significantly down-regulated at both time points was a Pelota gene (Additional file 3: Table S7), which was originally identified in Drosophila melanogaster and is known to function in meiosis [62]. In mouse, it has been reported that disruption of the Pelota gene causes early embryonic lethality and defects in cell cycle progression [63], and in plants, a single homologue has been identified in Arabidopsis [64]. Due to its known role in meiosis, it is highly possible that reduction of Pelota expression in grape could be related to $\mathrm{GA}_{3}$-induced seedlessness (Figure 2J).
To further pinpoint particular genes that may play an important function in the response to exogenous $\mathrm{GA}_{3}$, genes with $a \geq 10$-fold change between treated and untreated samples, and relating to more than one biological process, were identified. Interestingly, we found that genes encoding polygalacturonases (PGs) were substantially up-regulated in response to $\mathrm{GA}_{3}$ (Additional file 4), with two of these (GSVIVG01017354001 and GSVIVG01032117 001) being up-regulated in excess of 230-fold. PG activity has been shown to be associated with organ abscission $[65,66]$, pod and anther dehiscence [67], pollen grain maturation and pollen tube growth [68,69]. In grapevine, bloom coincides with the falling of cap structures, which are formed by the four petals detaching at the base of the flower to release the carpel and stamens. Most notably, these up-regulated $P G s$ genes in $\mathrm{GA}_{3}$-treated samples were found to be involved in both flower development and ripening biological processes. Therefore, one may speculate that the genes encoding these significantly up-regulated PGs play a vital role in the $\mathrm{GA}_{3}$-induced opening of grape flowers and ripening of grape berries. It is possible to surmise that up-regulated PGs directly induced opening of grape $\mathrm{GA}_{3}$-treated flowers, and indirectly accelerated the maturation process in $\mathrm{GA}_{3}$-treated samples.

Interestingly, we also demonstrated that genes encoding chalcone synthases, which are key enzymes in the flavonoid biosynthetic pathway, were up-regulated 22-66-fold $1 \mathrm{~h}$ following $\mathrm{GA}_{3}$ treatment. In addition, two genes encoding flavanone 3-hydroxylases (GSVIVG01009907001 and GSVIVG01018781001) were up-regulated $24 \mathrm{~h}$ after $\mathrm{GA}_{3}$ application (Additional file 2: Figure S11). Since flavonoids contribute to the pigmentation of many flowers and fruits [70], it is possible to surmise that these particular genes might exert an important function in $\mathrm{GA}_{3}$-induced fruit coloring in grape (Figure 2G-I).

Similarly, we found that most of the DEGs encoding PALs, which catalyze the first step in the biosynthesis of phenylpropanoids, were up-regulated following $\mathrm{GA}_{3}$ application (Additional file 2: Figures S7, S12). The phenylpropanoid pathway has been shown to be coordinated in ripening fruit with the activity of the enzymes involved in the synthesis of flavonoids [71], and many of the distinctive features of fleshy fruits, such as the appearance of characteristic color at ripening, are related to changes in the synthesis and accumulation of phenolic compounds [71]. Moreover, salicylic acid (SA), which can induce flowering, is known to be a downstream product of this pathway [72-74]. These results suggest that both the early opening of flowers and induction of fruit coloring in $\mathrm{GA}_{3}$-treated samples (Figure 2A-I) might be triggered, at least in part, by the increased expression of $P A L$ genes and synthesis of SA.

It has been reported previously that the $\mathrm{GA}_{3}$-induced modulation of redox homeostasis may also play a role in 
seed abortion [17]. Interestingly, in the present study, pathways including glutathione-mediated detoxification (Additional file 2: Figure S19) and removal of superoxide radicals (Additional file 2: Figure S20), which are both related to ROS scavenging and detoxification, were significantly affected post- $\mathrm{GA}_{3}$ treatment. Taken together, our findings lend credence to the proposition that $\mathrm{GA}_{3}$-induced morphological changes (Figure 2) comprise a very complex process, with changes in the expression of genes related to many aspects of plant development playing a role.

\section{Conclusions}

In the present study, we demonstrated that the pre-bloom application of $\mathrm{GA}_{3}$ to 'Kyoho' grapevine inflorescences promoted the opening of flowers and fruit coloring, and also induced seed abortion. Furthermore, our comparison of the global expression profiles of $\mathrm{GA}_{3}$ treated and untreated grape flowers indicated that the GA response was complex, with alterations in the expression of genes involved in a large number of processes. These findings imply that $\mathrm{GA}_{3}$-induced changes in the morphology of grape inflorescences may be related to the regulation of hormone biosynthesis and signaling, the levels of various transcription factors, changes in secondary metabolites, and the stability of redox homeostasis. Our results provide valuable information concerning genes and pathways that are differentially expressed during the early $\mathrm{GA}_{3}$-responsive phase ( $1 \mathrm{~h}$ and $24 \mathrm{~h}$ ), which will be useful for the further study of the $\mathrm{GA}_{3}$ response mechanism in grape.

\section{Availability of supporting data}

The datasets supporting the results of this article have been submitted to the Sequence Read Archive at NCBI (http://www.ncbi.nlm.nih.gov/sra). The submission code is SRP045605.

\section{Additional files}

Additional file 1: Table S1. Primers used for qRT-PCR. Table S2. Number of reads cleaned and mapped with Tophat following $\mathrm{GA}_{3}$ application from grape cv. 'Kyoho' flowers. Table S3. Correlation coefficients of transcriptome profiles among RNA-seq samples in grape cv. 'Kyoho' flowers. Table S4. Functional categorization of differentially expressed grape genes after $\mathrm{GA}_{3}$ treatment based on the biological process of Gene Ontology (GO). Table S5. List of differentially expressed grape genes following $\mathrm{GA}_{3}$ treatment related to cell death, flower development, pollen-pistil interaction, pollination, ripening, embryonic development and post-embryonic development. Values in red and green indicate the fold increase and decrease in expression in $\mathrm{GA}_{3}$-treated tissue, respectively. hpt: hours post treatment. Table S6. Functional categorization of differentially expressed grape genes after $\mathrm{GA}_{3}$ treatment based on the molecular function of Gene Ontology (GO). Table S7. Functional categorization of differentially expressed grape genes after $\mathrm{GA}_{3}$ treatment based on the cellular component of Gene Ontology (GO). Table S8. Differentially expressed grape genes with roles in GA biosynthesis and signaling following $\mathrm{GA}_{3}$ treatment. Values in red and green indicate the fold increase and decrease in expression in $\mathrm{GA}_{3}$-treated tissue, respectively. Values in yellow indicate $P$ value less than 0.05 . Table S9. Differentially expressed grape genes encoding transcription factors following $\mathrm{GA}_{3}$ treatment. Values in red and green indicate the fold increase and decrease in expression in $\mathrm{GA}_{3}$-treated tissue, respectively. Values in yellow indicate $P$ value less than 0.05 . Table S10. Differentially expressed grape genes with roles in biochemical pathways $1 \mathrm{~h}$ and $24 \mathrm{~h}$ after $\mathrm{GA}_{3}$ treatment with a $\mathrm{P}$ value cutoff of less than 0.05 .

Additional file 2: Figure S1. Changes in gibberellin content within grape flowers 6, 12, 18 and $24 \mathrm{~d}$ after $\mathrm{GA}_{3}$ treatment. Figure $\mathbf{S}$. Functional categorization of differentially expressed grape genes after $\mathrm{GA}_{3}$ treatment based on the molecular function of Gene Ontology (GO). Figure S3. Functional categorization of differentially expressed grape genes after $\mathrm{GA}_{3}$ treatment based on the cellular component of Gene Ontology (GO). Figure S4. Genes encoding members of transcription factor families that exhibited altered levels of expression following $\mathrm{GA}_{3}$ treatment. Figure S5. Correlation of fold-changes obtained by RNA-Seq platform ( $x$ axis) and quantitative real-time RT-PCR ( $y$ axis). Figure $\mathbf{S 6 .}$ Genes involved in the jasmonic acid biosynthetic pathway following $\mathrm{GA}_{3}$ treatment. Figure $\mathbf{S 7}$. Genes involved in the salicylate biosynthetic pathway following $\mathrm{GA}_{3}$ treatment. Figure $\mathbf{S 8}$. Genes involved in the ethylene biosynthetic pathway following $\mathrm{GA}_{3}$ treatment. Figure $\mathbf{5 9}$. Genes involved in the cytokinin degradative pathway following $\mathrm{GA}_{3}$ treatment. Figure S10. Genes involved in the farnesene biosynthetic pathway following $\mathrm{GA}_{3}$ treatment. Figure S11. Genes involved in the flavonoid biosythetic pathway following $\mathrm{GA}_{3}$ treatment. Figure $\mathbf{S 1 2}$. Genes involved in the phenylpropanoid biosynthetic pathway following $\mathrm{GA}_{3}$ treatment. Figure $\mathbf{S 1 3}$. Genes involved in the homogalacturonan biosynthetic and degradative pathways following $\mathrm{GA}_{3}$ treatment. Figure S14. Ggenes involved in the celluose biosynthetic pathway following $\mathrm{GA}_{3}$ treatment. Figure S15. Genes involved in the starch degradative pathway following $\mathrm{GA}_{3}$ treatment. Figure S16. Genes involved in the lactose degradation III pathway following $\mathrm{GA}_{3}$ treatment. Figure S17. Genes involved in the sucrose degradation I pathway following $\mathrm{GA}_{3}$ treatment. Figure S18. Genes involved in the 13-LOX and 13-HPL pathways following GA treatment. Figure S19. Genes involved in the glutathione-mediated detoxification pathway following $\mathrm{GA}_{3}$ treatment. Figure S20. Genes involved in the removal of superoxide radicals following $\mathrm{GA}_{3}$ treatment.

Additional file 3: Table S1. Genes that were up-regulated $1 \mathrm{~h}$ after $\mathrm{GA}_{3}$ treatment and exhibited no change in expression levels $24 \mathrm{~h}$ after $\mathrm{GA}_{3}$ treatment. Values in red indicate the fold increase in expression in $\mathrm{GA}_{3}-$ treated tissue. Values in yellow indicate $P$ value less than 0.05 . Table $\mathbf{S} 2$. Genes exhibiting no change in expression levels $1 \mathrm{~h}$ after $\mathrm{GA}_{3}$ treatment but were up-regulated $24 \mathrm{~h}$ after $\mathrm{GA}_{3}$ treatment. Values in red indicate the fold increase in expression in $\mathrm{GA}_{3}$-treated tissue. Values in yellow indicate $\mathrm{P}$ value less than 0.05 . Table S3. Genes that were down-regulated $1 \mathrm{~h}$ after $\mathrm{GA}_{3}$ treatment and exhibited no change in expression levels $24 \mathrm{~h}$ after $\mathrm{GA}_{3}$ treatment. Values in green indicate the fold decrease in expression in $\mathrm{GA}_{3^{-}}$ treated tissue. Values in yellow indicate $\mathrm{P}$ value less than 0.05 . Table $\mathbf{S 4}$. Genes exhibiting no change in expression levels $1 \mathrm{~h}$ after $\mathrm{GA}_{3}$ treatment but were down-regulated $24 \mathrm{~h}$ after $\mathrm{GA}_{3}$ treatment. Values in green indicate the fold decrease in expression in $\mathrm{GA}_{3}$-treated tissue. Values in yellow indicate $\mathrm{P}$ value less than 0.05 . Table S5. Genes that were down-regulated $1 \mathrm{~h}$ after $\mathrm{GA}_{3}$ treatment and up-regulated $24 \mathrm{~h}$ after $\mathrm{GA}_{3}$ treatment. Values in red and green indicate the fold increase and decrease in expression in $\mathrm{GA}_{3}$-treated tissue, respectively. Values in yellow indicate $P$ value less than 0.05 . Table $\mathbf{S 6 .}$ Genes that were up-regulated $1 \mathrm{~h}$ after $\mathrm{GA}_{3}$ treatment and down-regulated $24 \mathrm{~h}$ after $\mathrm{GA}_{3}$ treatment. Values in red and green indicate the fold increase and decrease in expression in $\mathrm{GA}_{3}$-treated tissue, respectively. Values in yellow indicate $P$ value less than 0.05 . Table S7. Genes that were down-regulated both $1 \mathrm{~h}$ and $24 \mathrm{~h}$ after $\mathrm{GA}_{3}$ treatment. Values in green indicate the fold decrease in expression in $\mathrm{GA}_{3}$-treated tissue. Values in yellow indicate $\mathrm{P}$ value less than 0.05 .

Additional file 4: Differentially expressed genes (fold changes $\geq 10$ ) following GA3 treatment related to more than one biological process.

\section{Abbreviations}

13-HPL: 13-hydro-peroxidelyase; 13-LOX: 13-lipoxygenase; ACS: 1-aminocyclopropane-1-carboxylate synthase; CKX: Cytokinin oxidase/ dehydrogenase; CPS: Ent-copalyl diphosphate synthase; CTK: Cytokinin; 
DAF: Days after full bloom; DEG: Differentially expressed gene; EST: Expressed sequence tag; FDR: False discovery rate; KS: Ent-kaurene synthase; KO: Ent-kaurene oxidase; GA: Gibberellic acid; GA20x: GA 2-oxidases; GA20ox: GA 20-oxidases; GA3ox: GA 3-oxidases; GAl: GA-Insensitive; GGDP: Geranylgeranyl diphosphateis; GID1: GA INSENSITIVE DWARF 1; GO: Gene Ontology; JAs: Jasmonates; KAO: Ent-kaurenoic acid oxidase; PAL: Phenylalanine ammonia-lyase; PG: Polygalacturonase; qRT-PCR: Quantitative real-time-PCR; RGA: Repressor of ga1-3; ROS: Reactive oxygen species; RPKM: Reads per kilobase of exon model per million mapped reads; SLY1: SLEEPY 1; TF: Transcription factor.

\section{Competing interests}

The authors declare that they have no competing interests.

\section{Authors' contributions}

XW CC: conceived and designed the experiments. CC, CJ and ZF: analyzed the data. CC, MG, XX and YZ: performed the experiments. XW, ZF, YW and $\mathrm{ZL}$ : contributed reagents/materials/analysis tools. XW: provided guidance on the whole study. CC XW: wrote the manuscript. SS: assisted with the interpretation of the results and provided editorial support for the manuscript. All authors approved the final manuscript.

\section{Acknowledgments}

This work was supported by the National Natural Science Foundation of China (31272136), 948 Project from Ministry of Agriculture of China (2012-S12), as well as the Program for Innovative Research Team of Grape Germplasm Resources and Breeding (2013KCT-25).

\section{Author details}

${ }^{1}$ State Key Laboratory of Crop Stress Biology in Arid Areas, College of Horticulture, Northwest A\&F University, Yangling 712100, Shaanxi, China. ${ }^{2}$ Key Laboratory of Horticultural Plant Biology and Germplasm Innovation in Northwest China, Ministry of Agriculture, Northwest A\&F University, Yangling 712100, Shaanxi, China. ${ }^{3}$ Department of Ornamental Horticulture, China Agricultural University, Beijing 100193, China. ${ }^{4}$ Department of Agricultural, Food and Nutritional Science, University of Alberta, Edmonton, AB T6G 2P5, Canada. ${ }^{5}$ Institute for Horticultural Plants, China Agricultural University, Beijing 100193, China. ${ }^{6}$ Boyce Thompson Institute for Plant Research, Cornell University, Ithaca, NY 14853, USA. ${ }^{7}$ USDA Robert W. Holley Center for Agriculture and Health, Ithaca, NY 14853, USA.

\section{Received: 5 September 2014 Accepted: 4 February 2015}

\section{Published online: 25 February 2015}

\section{References}

1. Hirano K, Ueguchi-Tanaka M, Matsuoka M. GID1-mediated gibberellin signaling in plants. Trends Plant Sci. 2008;13:192-9.

2. Kurosawa E. Experimental studies on the nature of the substance secreted by the "bakanae" fungus. Nat Hist Soc Formosa. 1926;16:213-27.

3. Olszewski N, Sun T-p, Gubler F. Gibberellin signaling: biosynthesis, catabolism, and response pathways. Plant Cell. 2002;14:S61-80.

4. Davies PJ. Plant hormones: physiology, biochemistry and molecular biology. The Netherlands: Kluwer Academic Dordrecht; 1995.

5. Lange T. Molecular biology of gibberellin synthesis. Planta. 1998;204:409-19.

6. Kamiya Y, García-Martínez JL. Regulation of gibberellin biosynthesis by light. Curr Opin Plant Biol. 1999:2:398-403.

7. Hedden P, Phillips AL. Gibberellin metabolism: new insights revealed by the genes. Trends Plant Sci. 2000;5:523-30.

8. Yamaguchi S, Kamiya Y. Gibberellin biosynthesis: its regulation by endogenous and environmental signals. Plant Cell Physiol. 2000;41:251-7.

9. Lovegrove A, Hooley R. Gibberellin and abscisic acid signalling in aleurone. Trends Plant Sci. 2000;5:102-10

10. Richards DE, King KE, Ait-ali T, Harberd NP. How gibberellin regulates plant growth and development: a molecular genetic analysis of gibberellin signaling. Annu Rev Plant Biol. 2001;52:67-88.

11. Claeys H, De Bodt S, Inzé D. Gibberellins and DELLAs: central nodes in growth regulatory networks. Trends Plant Sci. 2013.

12. T-p S. Gibberellin signal transduction. Curr Opin Plant Biol. 2000;3:374-80

13. Thornton TM, Swain SM, Olszewski NE. Gibberellin signal transduction presents... the SPY who O-GICNAc'd me. Trends Plant Sci. 1999;4:424-8.
14. T-p S. The molecular mechanism and evolution of the GA-GID1-DELLA signaling module in plants. Curr Biol. 2011;21:R338-45.

15. Fleet CM, Sun T-p. A DELLAcate balance: the role of gibberellin in plant morphogenesis. Curr Opin Plant Biol. 2005;8:77-85.

16. Shan X, Yan J, Xie D. Comparison of phytohormone signaling mechanisms. Curr Opin Plant Biol. 2012;15:84-91.

17. Cheng $C, X u X$, Singer SD, Li J, Zhang $H$, Gao M, et al. Effect of $G A_{3}$ treatment on seed development and seed-related gene expression in grape. PLoS ONE. 2013;8:e80044

18. Kimura PH, Okamoto G, Hirano K. Effects of gibberellic acid and streptomycin on pollen germination and ovule and seed development in Muscat Bailey A. Am J Enol Viticult. 1996;47:152-6.

19. Iwahori S, Weaver RJ, Pool RM. Gibberellin-like activity in berries of seeded and seedless Tokay grapes. Plant Physiol. 1968;43:333-7.

20. Wang Z, Zhao F, Zhao X, Ge H, Chai L, Chen S, et al. Proteomic analysis of berry-sizing effect of $\mathrm{GA}_{3}$ on seedless Vitis vinifera L. Proteomics. 2012;12:86-94.

21. Boss PK, Thomas MR. Association of dwarfism and floral induction with a grape 'green revolution' mutation. Nature. 2002;416:847-50.

22. Agüero C, Vigliocco A, Abdala G, Tizio R. Effect of gibberellic acid and uniconazol on embryo abortion in the stenospermocarpic grape cultivars Emperatriz and Perlon. Plant Growth Regul. 2000;30:9-16.

23. Okamoto G, Miura K. Effect of pre-bloom GA application on pollen tube growth in cv. Delaware grape pistils. Vitis. 2005;44:157.

24. Hittinger $C T$, Johnston M, Tossberg JT, Rokas A. Leveraging skewed transcript abundance by RNA-Seq to increase the genomic depth of the tree of life. Proc Natl Acad Sci USA. 2010;107:1476-81.

25. Jaillon O, Aury J-M, Noel B, Policriti A, Clepet C, Casagrande A, et al. The grapevine genome sequence suggests ancestral hexaploidization in major angiosperm phyla. Nature. 2007;449:463-7.

26. Velasco R, Zharkikh A, Troggio M, Cartwright DA, Cestaro A, Pruss D, et al. A high quality draft consensus sequence of the genome of a heterozygous grapevine variety. PLOS ONE. 2007;2:e1326.

27. Han J, Fang J, Wang C, Yin Y, Sun X, Leng X, et al. Grapevine microRNAs responsive to exogenous gibberellin. BMC Genomics. 2014;15:111.

28. Sugiura A, Inaba A. Studies on the mechanism of gibberellin-induced seedlessness of Delaware grapes. I. Effect of pre-bloom gibberellin treatment on pollen germination. J Jpn Soc Hort Sci. 1966;35:233-41.

29. Zhang XZ, Zhao YB, Wang GP, Chang RF, Li CM, Shu HR. Dynamics of endogenous cytokinins during phase change in Malus domestica Borkh. Acta Hort. 2008;774:29-33.

30. Zhong S, Joung J-G, Zheng Y, Chen Y-r, Liu B, Shao Y, et al. High-throughput illumina strand-specific RNA sequencing library preparation. Cold Spring Harb Protoc. 2011;2011:940-9.

31. Langmead B, Trapnell C, Pop M, Salzberg SL. Ultrafast and memory-efficient alignment of short DNA sequences to the human genome. Genome Biol. 2009;10:R25

32. Trapnell C, Pachter L, Salzberg SL. TopHat: discovering splice junctions with RNA-Seq. Bioinformatics. 2009;25:1105-11.

33. Anders $\mathrm{S}$, Huber $\mathrm{W}$. Differential expression analysis for sequence count data. Genome Biol. 2010;11:R106.

34. Benjamini Y, Hochberg Y. Controlling the false discovery rate: a practical and powerful approach to multiple testing. J Royal Stat Soc Series B (Methodological). 1995;57:289-300.

35. Joung J-G, Corbett AM, Fellman SM, Tieman DM, Klee HJ, Giovannoni Jر, et al. Plant MetGenMAP: an integrative analysis system for plant systems biology. Plant Physiol. 2009;151:1758-68.

36. Peter H, Stephen GT. Gibberellin biosynthesis and its regulation. Biochem J. 2012:444:11-25.

37. Coombe BG. Relationship of growth and development to changes in sugars, auxins, and gibberellins in fruit of seeded and seedless varieties of Vitis vinifera. Plant Physiol. 1960;35:241.

38. Gustafson FG. Inducement of fruit development by growth-promoting chemicals. Proc Natl Acad Sci USA. 1936;22:628-36.

39. Mesejo C, Martínez-Fuentes A, Reig C, Agustí M. Gibberellic acid impairs fertilization in Clementine mandarin under cross-pollination conditions. Plant Sci. 2008;175:267-71.

40. Kondhare KR, Hedden P, Kettlewell PS, Farrell AD, Monaghan JM. Quantifying the impact of exogenous abscisic acid and gibberellins on pre-maturity a-amylase formation in developing wheat grains. Sci Rep. 2014;4:5355 
41. Piotrowska A, Bajguz A. Conjugates of abscisic acid, brassinosteroids, ethylene, gibberellins, and jasmonates. Phytochemistry. 2011;72:2097-112.

42. Peng J. Gibberellin and jasmonate crosstalk during stamen development. J Integr Plant Biol. 2009;51:1064-70.

43. Cheng H, Song S, Xiao L, Soo HM, Cheng Z, Xie D, et al. Gibberellin acts through jasmonate to control the expression of MYB21, MYB24, and MYB57 to promote stamen filament growth in Arabidopsis. PLoS Genet. 2009;5:e1000440.

44. Feys BJ, Benedetti CE, Penfold CN, Turner JG. Arabidopsis mutants selected for resistance to the phytotoxin coronatine are male sterile, insensitive to methyl jasmonate, and resistant to a bacterial pathogen. Plant Cell. 1994;6:751-9.

45. McConn M. The critical requirement for linolenic acid is pollen development, not photosynthesis, in an Arabidopsis mutant. Plant Cell. 1996:8:403-16.

46. Cheng H, Qin L, Lee S, Fu X, Richards DE, Cao D, et al. Gibberellin regulates Arabidopsis floral development via suppression of DELLA protein function. Development. 2004;131:1055-64.

47. Mandaokar A, Thines B, Shin B, Markus Lange B, Choi G, Koo YJ, et al. Transcriptional regulators of stamen development in Arabidopsis identified by transcriptional profiling. Plant J. 2006;46:984-1008.

48. Song S, Qi T, Huang H, Ren Q, Wu D, Chang C, et al. The jasmonate-ZIM domain proteins interact with the R2R3-MYB transcription factors MYB21 and MYB24 to affect jasmonate-regulated stamen development in Arabidopsis. Plant Cell. 2011;23:1000-13.

49. Ashikari M, Sakakibara H, Lin S, Yamamoto T, Takashi T, Nishimura A, et al. Cytokinin oxidase regulates rice grain production. Science. 2005;309:741-5.

50. Bartrina I, Otto E, Strnad M, Werner T, Schmülling T. Cytokinin regulates the activity of reproductive meristems, flower organ size, ovule formation, and thus seed yield in Arabidopsis thaliana. Plant Cell. 2011;23:69-80.

51. Marsch-Martínez N, Ramos-Cruz D, Irepan Reyes-Olalde J, Lozano-Sotomayor P, Zúñiga-Mayo VM, de Folter S. The role of cytokinin during Arabidopsis gynoecia and fruit morphogenesis and patterning. Plant J. 2012;72:222-34.

52. Argueso CT, Raines T, Kieber JJ. Cytokinin signaling and transcriptional networks. Curr Opin Plant Biol g. 2010;13:533-9.

53. Müller B, Sheen J. Advances in cytokinin signaling. Science. 2007;318:68-9.

54. Werner T, Schmülling T. Cytokinin action in plant development. Curr Opin Plant Biol. 2009;12:527-38.

55. Argueso CT, Hansen M, Kieber JJ. Regulation of ethylene biosynthesis. J Plant Growth Regul. 2007;26:92-105.

56. Achard P, Baghour M, Chapple A, Hedden P, Van Der Straeten D, Genschik $P$, et al. The plant stress hormone ethylene controls floral transition via DELLA-dependent regulation of floral meristem-identity genes. Proc Natl Acad Sci USA. 2007;104:6484-9.

57. Ribeiro DM, Araújo WL, Fernie AR, Schippers JH, Mueller-Roeber B. Translatome and metabolome effects triggered by gibberellins during rosette growth in Arabidopsis. J Exp Bot. 2012;63:2769-86.

58. Elliott RC, Ross JJ, Smith JJ, Lester DR, Reid JB. Feed-forward regulation of gibberellin deactivation in pea. J Plant Growth Regul. 2001;20:87-94.

59. Thomas SG, Phillips AL, Hedden P. Molecular cloning and functional expression of gibberellin 2-oxidases, multifunctional enzymes involved in gibberellin deactivation. Proc Natl Acad Sci USA. 1999:96:4698-703.

60. Hartweck LM. Gibberellin signaling. Planta. 2008;229:1-13.

61. Jung $\mathrm{CJ}$, Hur YY, Yu H-J, Noh J-H, Park K-S, Lee HJ. Gibberellin application at pre-bloom in grapevines down-regulates the expressions of VVIAA9 and VVARF7, negative regulators of fruit set Initiation, during parthenocarpic fruit development. PLoS ONE. 2014;9:e95634.

62. Castrillon DH, Gonczy P, Alexander S, Rawson R, Eberhart CG, Viswanathan S, et al. Toward a molecular genetic analysis of spermatogenesis in Drosophila melanogaster: characterization of male-sterile mutants generated by single E-element mutagenesis. Genetics. 1993;135:489-505.

63. Adham IM, Sallam MA, Steding G, Korabiowska M, Brinck U, Hoyer-Fender S, et al. Disruption of the Pelota gene causes early embryonic lethality and defects in cell cycle progression. Mol Cell Biol. 2003;23:1470-6.

64. Caryl AP, Lacroix I, Jones GH, Franklin FCH. An Arabidopsis homologue of the Drosophila meiotic gene Pelota. Sex Plant Reprod. 2000;12:310-3.

65. Taylor JE, Tucker GA, Lasslett Y, Smith CJ, Arnold CM, Watson CF, et al. Polygalacturonase expression during leaf abscission of normal and transgenic tomato plants. Planta. 1991;183:133-8.

66. Bonghi C, Rascio N, Ramina A, Casadoro G. Cellulase and polygalacturonase involvement in the abscission of leaf and fruit explants of peach. Plant Mol Biol. 1992;20:839-48.
67. Meakin PJ, Roberts JA. Anatomical and biochemical changes associated with the induction of oilseed rape (Brassica napus) pod dehiscence by Dasineura brassicae (Winn.). Ann Bot. 1991;67:193-7.

68. Pressey R, Reger BJ. Polygalacturonase in pollen from corn and other grasses. Plant Sci. 1989;59:57-62.

69. Pressey R. Polygalacturonase in tree pollens. Phytochemistry. 1991;30:1753-5.

70. Schijlen EG, Ric de Vos C, van Tunen AJ, Bovy AG. Modification of flavonoid biosynthesis in crop plants. Phytochemistry. 2004;65:2631-48.

71. Cheng GW, Breen PJ. Activity of phenylalanine ammonia-lyase (PAL) and concentrations of anthocyanins and phenolics in developing strawberry fruit. J Amer Soc Hort Sci. 1991;116:865-9.

72. Yalpani N, Leon J, Lawton MA, Raskin I. Pathway of salicylic acid biosynthesis in healthy and virus-inoculated tobacco. Plant Physiol. 1993:103:315-21.

73. Kandeler R. Lemnaceae. Handb Flowering. 1985;3:251-79.

74. Wada KC, Mizuuchi K, Koshio A, Kaneko K, Mitsui T, Takeno K. Stress enhances the gene expression and enzyme activity of phenylalanine ammonia-lyase and the endogenous content of salicylic acid to induce flowering in pharbitis. J Plant Physiol. 2014;171:895-902.

\section{Submit your next manuscript to BioMed Central and take full advantage of:}

- Convenient online submission

- Thorough peer review

- No space constraints or color figure charges

- Immediate publication on acceptance

- Inclusion in PubMed, CAS, Scopus and Google Scholar

- Research which is freely available for redistribution 